\title{
Profil Pertumbuhan Baringtonia asiatica pada Teluk Wosidori Kabupaten Manokwari
}

\author{
Delis Mundoni' ${ }^{1}$; Rima H S Siburian ${ }^{2}$ \\ Fakultas Kehutanan Universitas Papua, Indonesia \\ r.siburian@uipa.ac.id
}

\begin{abstract}
Abstrak
Baringtonia asiatica merupakan salah satu tumbuhan mangrove yang hidup di daerah pesisir pantai. Tumbuhan ini memiliki nilai manfaat sebagai tanaman obat dan juga bioekologi. B. asiatica banyak ditemukan di Teluk Wosidori, namun bagaimana profil pertumbuhan tumbuhan tersebut, perlu dilakukan penelitian ini sebagai data awal bagi pengembangan jenis ini. Penelitian ini bertujuan untuk mengetahui profil pertumbuhan dan penyebaran Baringtonia asiatica dan metode yang digunakan adalah metode deskriptif dengan teknik survey. Variabel yang diamati dalam penelitian ini adalah profil penyebaran B.asiatica. Hasil penelitian menunjukkan bahwa kondisi tempat tumbuh B.asiatica pada Teluk Wosidori sudah sangat mengkhawatirkan karena menurunnya luasan hutan yang ada, yang disebabkan oleh alih fungsi lahan, serta aktifitas manusia. Hal ini nampak juga pada data potensi pohon yang ditemukan paling banyak 9 pohon pada daerah Sowi 4. Sedangkan pola penyebaran tumbuhan B.asiatica lebih mengelompok.
\end{abstract}

Kata kunci: Profil, Baringtonia asiatica, Teluk Wosidori.

\section{PENDAHULUAN}

Kawasan hutan mangrove memiliki potensi dan keunikan sumberdaya alam yang sangat berperan dalam pengembangan ekonomi, sosial, budaya, dan lingkungan. Arifian (2014) mengatakan bahwa ekosistem mangrove sangat berperan dalam menjaga kelangsungan makhluk hidup yang hidup dan berkembang pada kawasan tersebut. Pengelolaan lingkungan pada kawasan ini menjadi bagian yang sangat penting terutama dalam mendukung upaya pengembangan wilayah pesisir secara optimal, bijaksana, dan bertanggung jawab, dengan melibatkan masyarakat dari berbagai pihak dengan tetap memperhatikan daya dukung lingkungan hutan mangrove. Partisipasi serta pelibatan masyarakat ini menjadi faktor pendukung yang sangat penting dalam pengembangan wilayah pesisir serta menjaga dan melestarikan kawasan dengan berbagai upaya perlindungan atau perbaikan Kawasan Hutan Mangrove.

Potensi yang terdapat pada kawasan hutan mangrove secara umum dapat dimanfaatkan secara optimal, bijaksana, dan berkelanjutan bila aspek ekonomi, sosial dan lingkungan atau ekologi dapat berjalan berdampingan. Namun sebaliknya apabila terdapat ketidak serasian dari ketiga aspek tersebut akan menimbulkan dampak negatif terutama pada daerah kawasan dan ekologi daerah setempat (Wabia dan Siburian, 2019)

Baringtonia asiatica merupakan salah satu tumbuhan mangrove yang tumbuh pada kawasan litoral yang ekslusif, dan umumnya ditemukan pada pantai berpasir atau koral pasir, disepanjang pantai atau rawa mangrove pada ketinggian 0-350 meter di atas permukaan laut. B. asiatica ini umumnya digunakan masyarakat sebagai obat tradisional untuk pengobatan sakit perut, rematik, dan juga dalam pengobatan luka. Buah tanaman 


\section{Median Volume 11 Nomor 3 Bulan Oktober 2019}

Doi http://doi.org/md.v11i3.141

ini mengandung saponin dan triterponid yang bila dieksetraksikan dengan beberapa jenis tanaman lainnya sehingga dapat bermanfaat bagi manusia (Septiarusli, 2012). Disamping itu biji buah tumbuhan ini juga dapat menyebabkan iritasi pada mata ikan.

Nilai manfaat $B$. asiatica selain sebagai tumbuhan obat-obatan, juga merupakan salah satu pohon yang berfungsi sebagai penjaga atau pelindung pantai, karena sistem perakarannya kuat dan kokoh sehingga mampu meredam gelombang pasang dan angin kencang sehingga mampu melindungi kawasan pantai dari erosi. Namun sejalan dengan pertumbuhan penduduk dan peningkatan kebutuhan manusia, kondisi $B$. asiatica dihabitatnya semakin memprihatinkan. Kawasan Teluk Wosidori merupakan salah satu kawasan yang ditumbuhi oleh vegetasi B.asiatica. Namun saat ini kawasan teluk ini menjadi lokasi pengembangan daerah pemukiman, perkantoran dan pelebaran jalan Propinsi Papua Barat. Informasi mengenai pola penyebaran jenis $B$. asiatica pada kawasan Teluk Wosidori Arfai, menjadi informasi penting yang perlu diketahui untuk

menjaga kelestarian jenis ini serta keberadaan jenis sebagai penjaga/ barrier pesisir pantai.

\section{METODE PENELITIAN}

Penelitian ini dilakukan di pantai Teluk Wasidori Arfai, Manokwari, Papua Barat. Adapun peralatan yang digunakan dalam penelitian ini adalah GPS (Global Position System), Kamera, parang, tally sheet, pita ukur, alat tulis, sedangkan objek yang diamati dalam penelitian ini adalah $B$. asiatica. Metode yang digunakan dalam penelitian ini adalah metode deskriptif dengan teknik survey, serta observasi langsung di lapangan. Variabel yang diamati adalah profil penyebaran B.asiatica. Jenis data yang dikumpulkan dalam penelitian ini adalah data primer berupa data B.asiatica dan data sekunder seperti kondisi umum lokasi penelitian. Data yang diperoleh kemudian diolah secara tabulasi dan disajikan dalam bentuk Gambar dan Tabel.

\section{HASIL DAN PEMBAHASAN}

\section{Keadaan Umum Lokasi Penelitian}

Pesisir pantai Wosidori Arfai Terletak pada posisi $134^{\circ} 3{ }^{`} 00 \mathrm{BT}-0^{\circ} 55^{`} 30 \mathrm{LS}$ kurang lebih $23 \mathrm{~km}$ di sebelah selatan kota Manokwari. Adapun lokasi penelitian, seperti pada Gambar 1.

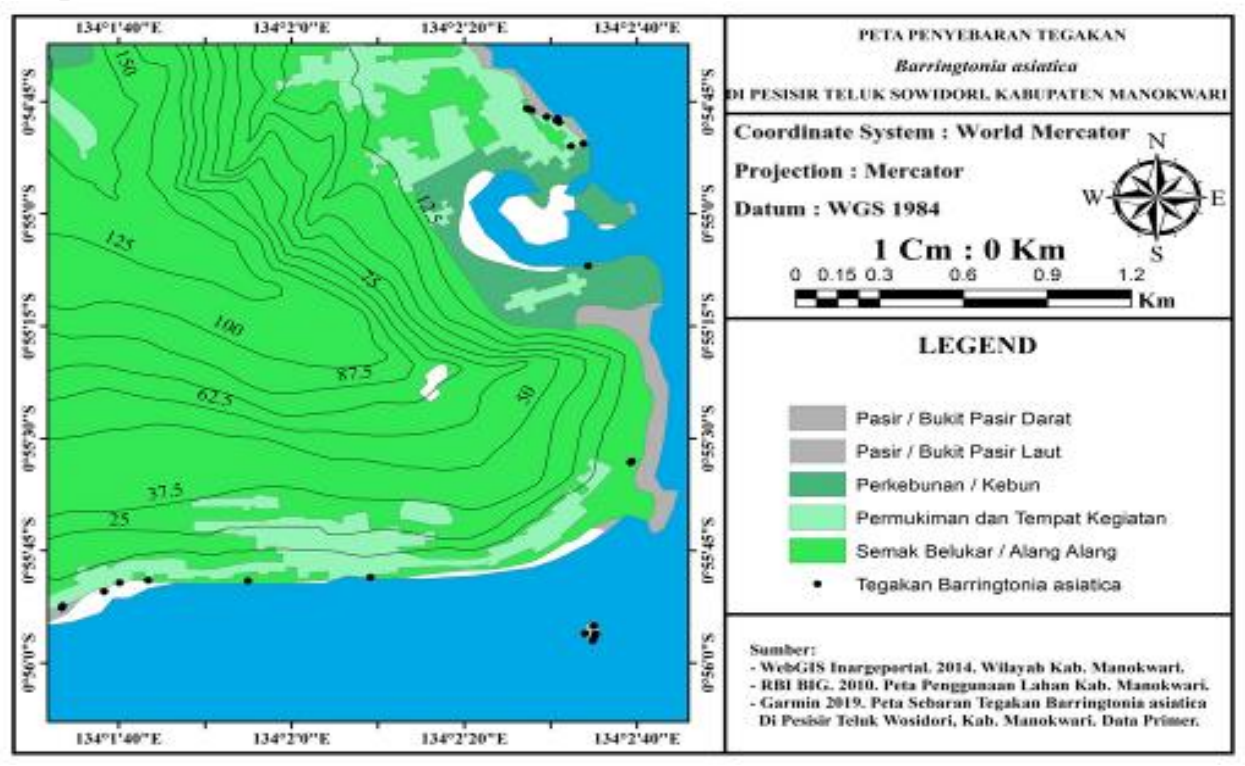




\section{Median Volume 11 Nomor 3 Bulan Oktober 2019}

Doi http://doi.org/md.v11i3.141

Gambar 1. Peta lokasi Penelitian pada Teluk Wosidori, Manokwari

Wilayah pesisir ini merupakan daerah teluk yang terhubung langsung dengan laut bebas. Pada kawasan pesisir ditumbuhi mangrove seperti famili Sonneratiaceae dan Rhizophoreceae (Wambrauw dan Pattiasina, 2005). Wilayah pesisir ini memiliki 3 ekosistem penting, yaitu ekosistem mangrove, ekosistem lamun dan ekosistem terumbu karang, dengan berbagai organisme yang berasosiasi di dalamnya.

Kawasan ini berada pada Distrik Manokwari Selatan dimana berdasarkan Data BPS hasil proyeksi penduduk tahun 2016 jumlah penduduk pada daerah ini sebanyak 14,731 jiwa dengan komposisi 7,900 jiwa penduduk laki-laki dan 6,831 jiwa penduduk perempuan. Selain itu disekitar kawasan ini juga telah dibangun beberapa bangunan perkantoran, ruko, pemukiman serta jalan. Oleh karena itu deforestasi hutan mangrove dipengaruhi juga oleh kegiatan masyarakat sekitar yang mengeksploitasi mangrove bagi pemenuhan kebutuhan sehari-hari, tanpa memperhatikan kelestarian mangrove.

\section{Potensi Barringtonia asiatica pada Teluk Wosidori}

Berdasarkan hasil pengamatan pada kawasan pesisir Pantai Teluk Wosidori untuk potensi $B$. asiatica, ditemukan pada beberapa tempat disepanjang teluk, seperti pada Tabel 1.

Tabel 1 . Tumbuhan Inang Barringtonia asiatica di Pesisir Pantai Teluk Wosidori.

\begin{tabular}{ccc}
\hline \multirow{2}{*}{ Lokasi } & \multicolumn{2}{c}{ Jumlah pohon induk } \\
\cline { 2 - 3 } & Diameter $>40 \mathrm{~cm}$ & Diameter $<40 \mathrm{~cm}$ \\
\hline Sowi 4 & 2 & 7 \\
Telaga Wasti & 1 & - \\
Pantai Dosa & 2 & - \\
Pantai Arfai 1 & 5 & - \\
Pantai Arfai Base camp & 2 & - \\
\hline
\end{tabular}

Pada umumnya potensi hutan pantai memiliki tingkat keanekaragaman jenis yang rendah (Tuheteru, 2012). Hal ini disebabkan karena kondisi hutan pantai umumnya tersusun oleh substrat pasir, yang sangat peka terhadap erosi bahkan menyulitkan tumbuhan untuk bertumbuh dan berkembang dengan baik. Selanjutnya Sunarto (2003) mengatakan bahwa pembentukan pantai secara morfologi terbentuk oleh proses terestrial baik erosi, deposisi, vulkanisme dan diatrofisme.

\section{Pola Sebaran Baringtonia asiatica}

Pola penyebaran B.asiatica pada daerah teluk Wosidori, ditemukan tumbuh secara mengelompok. Hal ini sesuai dengan perhitungan indeks Morisita, dimana derajat Morisita menunjukkan bila nilai hasil perhitungan $>0$ menunjukkan bahwa penyebaran spesies tersebut digolongkan dalam kategori mengelompok, seperti pada Tabel 2.

Tabel 2 Pola Sebaran B. Asiatica Berdasarkan Indeks Morisita

\begin{tabular}{ccc}
\hline Lokasi Pengamatan & Indeks Morisita & Pola sebaran \\
\hline Sowi 4 & 0.82 & Mengelompok \\
Telaga Wasti & 0.72 & Mengelompok \\
Pantai Dosa & 0.73 & Mengelompok \\
Pantai Arfai 1 & 0.78 & Mengelompok \\
Pantai Arfai Basecamp & 0.96 & Mengelompok \\
\hline
\end{tabular}




\section{Median Volume 11 Nomor 3 Bulan Oktober 2019}

Doi http://doi.org/md.v11i3.141

Pola penyebaran tumbuhan B.asiatica sangat dipengaruhi oleh faktor lingkungan. Buah B.asiatica yang jatuh akan dibawa oleh ombak yang kemudian terdampar dan tumbuh pada daerah yang cocok bagi pertumbuhan tumbuhan tersebut (Baransano et al. 2019; Siburian et. al., 2017). Selain penyebaran tumbuhan B. asiatica oleh ombak, tumbuhan ini juga sengaja ditanam oleh beberapa masyarakat direal pekarangan rumah mereka terutama warga yang tinggal berbatasan langsung dengan daerah pesisir, seperti pada Gambar 2.

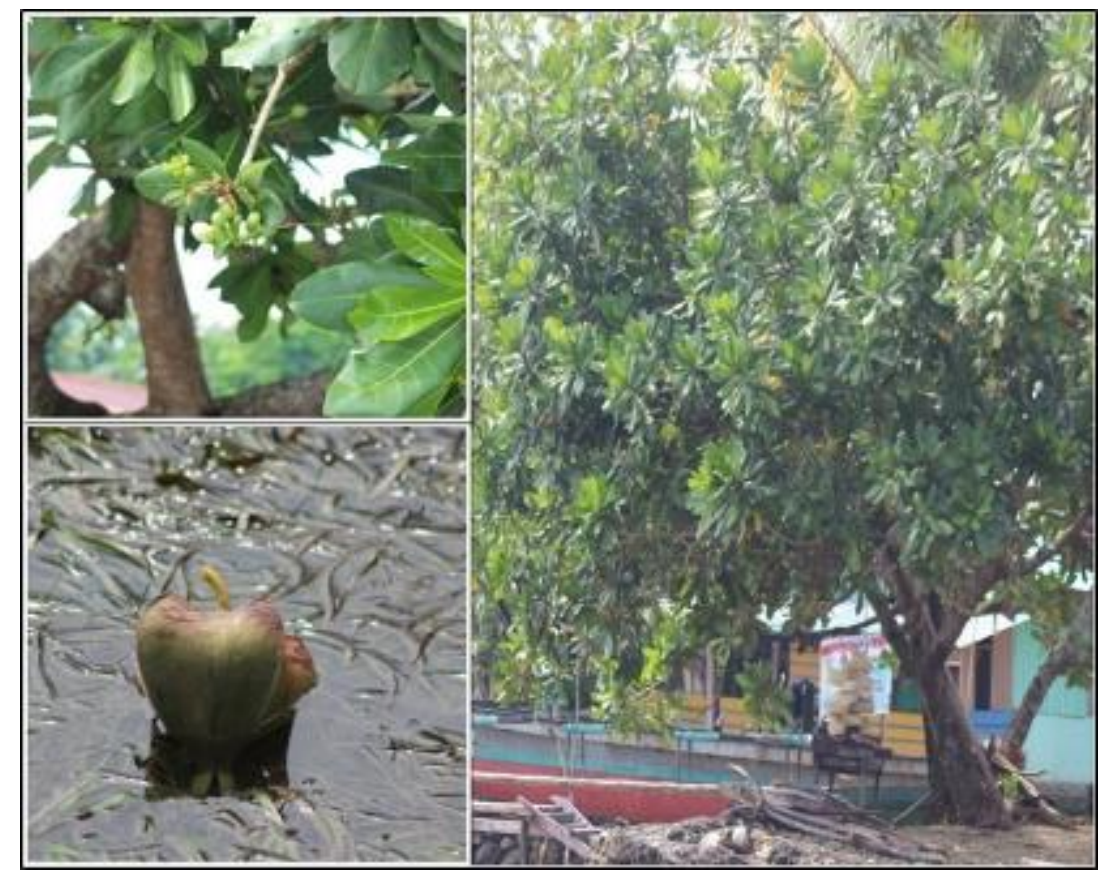

Gambar 2. Pohon B. asiatica yang Ditanam oleh Masyarakat

Pola penyebaran individu tanaman sangat tergantung pada faktor lingkungan serta kemampuan biologis tumbuhan tersebut dalam beradaptasi dengan habitat tempat tumbuhnya. Sartika et al. (2017) menyatakan bahwa pola penyebaran individu ada tiga macam yaitu penyebaran secara acak, merata dan mengelompok. Informasi tentang pola penyebaran sangat berperan dalam pengembangan jenis, terutama faktor bioekologi tumbuhan.

Faktor bioekologi yang mempengaruhi pertumbuhan tanaman diantaranya adalah faktor fisik seperti suhu udara disekitar tempat tumbuh, kelembaban, serta intensitas cahaya, tanah dan kondisi fisik lingkungan lainnya. Kesesuaian suatu jenis terhadap kondisi fisik lingkungan sangat bervariasi, hal ini akan sangat berdampak pada keragaman jenis tanaman (Siburian et.al, 2019).

\section{KESIMPULAN}

B. asiatica merupakan tumbuhan mangrove yang dijumpai di Teluk Wosidori, tersebar di 5 lokasi penelitian. Pola penyebaran jenis ini dilokasi penelitian adalah mengelompok. 


\section{Median Volume 11 Nomor 3 Bulan Oktober 2019}

Doi http://doi.org/md.v11i3.141

\section{DAFTAR PUSTAKA}

Arifian MA, 2014. Keanekaragaman dan Pola sebaran spesies invasive di Cagar Alam Bojonglarang Jayanti Cianjur. Skripsi. Institut Pertanian Bogor. (Tidak diterbitkan).

Baransano. F, Siburian R H, Angrianto R. 2019. Potensi Flindersia pimelentiana F. Muel di Kabupaten Manokwari Selatan. Median jurnal. Vo. 11. 1. 10-16.

Sartika, Setiawan A, Master J. 2017. Populasi Dan Pola Penyebaran Kantong Semar (Nepenthes gracilis) Di Rhino Camp Resort Sukaraja Atas Kawasan Taman Nasional Bukit Barisan Selatan (BBSNP). Jurnal Sylva Lestari Vol. 5 (3). 12 -21.

Septiarusli I E, Haetami K, Mulyani Y, Dono D. 2012. Potensi Senyawa Metabolit Sekunder dari ekstrak biji buah keben (Baringtonia asiatica) dalam Proses Anestesi ikan kerapu Macan (Ephinephelus fuscoguttatus). Jurnal Ikan dan Kelautan Vol 3. Nomor 3, September 2012, 295-299.

Siburian, R. H. S., Siregar U. Siregar I. (2017). Genetic variation of Gyrinops verstegii originated from Papua based on RAPD. Asian Journal of Microbiology, Biotechnology and Environmental Sciences. 19(3): 1-9.

Siburian, RH, Siregar U, Siregar I, Santoso, E. 2019. The Genotype Of Aquilaria Microcarpa Interacting With Fusarium Sp Based On Microsatellite Marker. Asian Journal of MicrobiOlogy, Biotech. Environment Science. Vol. 21. (2) (363-368).

Sunarto, 2003. Geomorfologi Pantai : Dinamika Pantai, Laboratorium Geomorfologi Terapan, Jurusan Geografi Fisik, Fakultas Geografi Universitas Gadjah Mada, Yogyakarta.

Tuheteru F. 2012. Ekologi, Manfaat \& Rehabilitasi Hutan Pantai Indonesia. Balai Penelitian Kehutanan Manado. Manado.

Wabia, E., Siburian H. S. 2019. Profil Tempat Tumbuh Sarang Semut (Myrmecodia spp.) Di Distrik Manokwari Selatan Papua Barat. Hal 91-94 DOI: 10.20527/ es.v15i1.6328.

Wambrauw ET. Pattiasina TF. 2005. Srtuktur komunitas dan penyebaran Mangrove di Pesisir Pantai Wosidori Arfai Kabupaten Manokwari. Jurnal Perikanan dan Kelautan 1 (1), 1-10. 